\title{
Dear Grandma
}

Cite as: CMAJ 2021 January 25;193:E139-40. doi: 10.1503/cmaj.202444

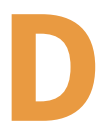

ear Grandma,

In February you caught a cold. With a sniffle on the phone you asked us to stay away, stay at home, while you recovered. But as we continued with the flow of life, that drip into your lungs wreaked havoc; it invaded the space, filling every crack. It dragged you to the hospital and demanded attention. We rushed into your room, spilling through the doorway to see your face, to make sure you were okay. And as the drugs took hold you were. The pneumonia melted away and the blue faded from your complexion, and we all let out the breath we did not know we had been holding.

In March you moved into our house. Despite your beloved smile surfacing again, your hospital stay had drained you. The mundane became laboursome, the once difficult now impossible. We hugged you and kissed you and told you how nice it was to spend this time with our grandma. We sat in your room with you and watched TV. We made you sandwiches and laughed about our poor genetics for cooking. We pretended not to notice when things were not looking better anymore, but worse. Your wheezes flooded our ears, threatening our illusion that you would one day return to your home. We rationalized and reasoned and justified and explained when you needed more and more oxygen to sit in your chair, until finally the realization crested, broke and came crashing down on us: you were drowning, and we had nothing left to pull you to shore.

By April you asked us if you could die at home. We cringed at the sound of the word death, not yet ready to accept it, but knew that a death at home was what you had wanted all along. Your realist's approach to life meant that we had

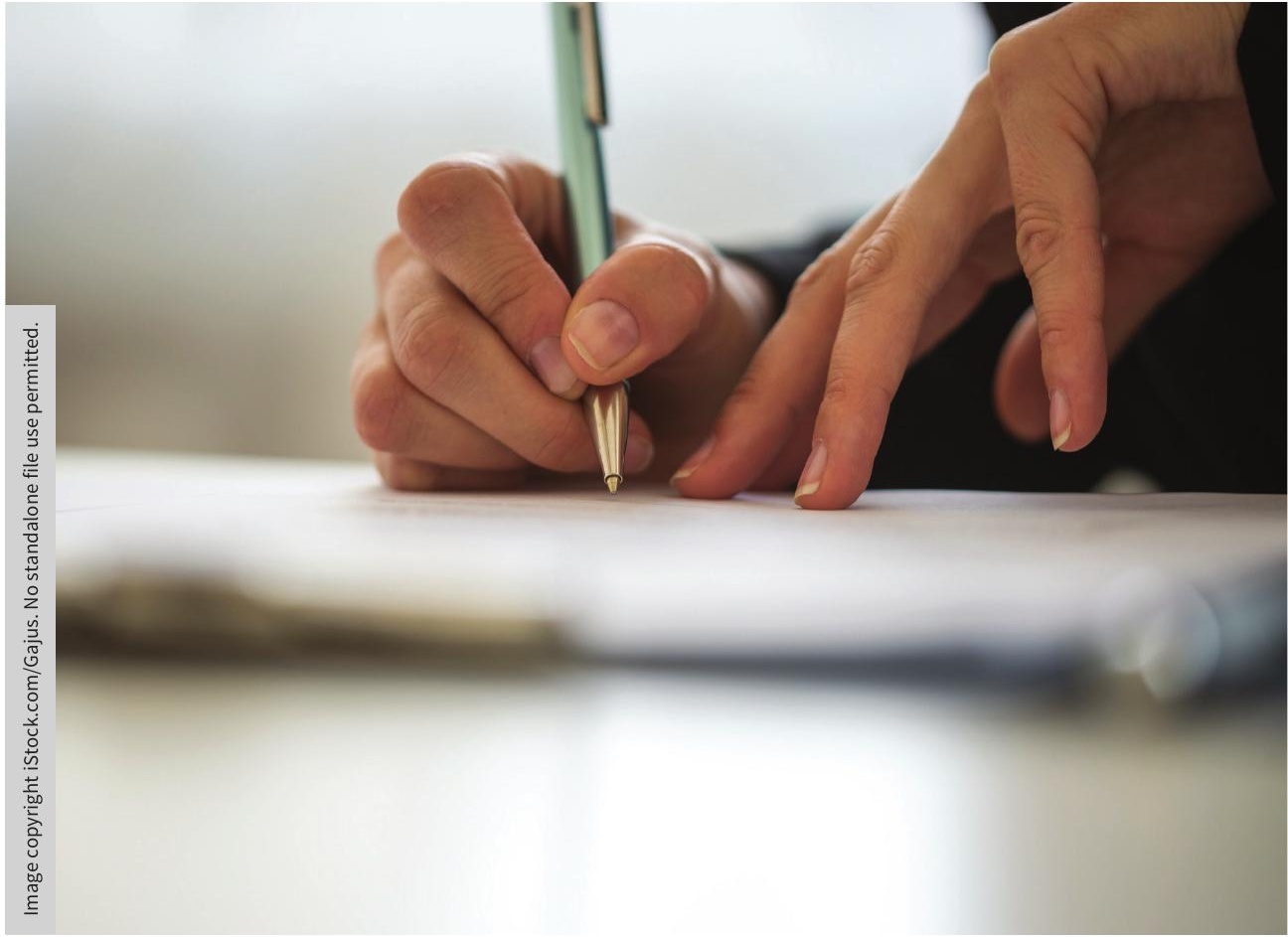

already talked about where you wanted to be when the last breaths of your life passed. Despite these frank conversations, we had never thought further about what dying at home might look like, scared that talking about it might cause it to come to fruition. And in that span of time we spent trying to figure out what your dying days would entail, you had your dying days. Your body grew weaker as your organs began to betray you. The fluid seeped back into your lungs, threatening to pull you under. Every breath became a gasp. Timelines that we thought were months down the road accelerated while we scrambled around the house trying desperately to comfort you, overcome with our fear that by keeping you at home we were causing the suffering you had wanted to avoid. The combined anxiety of caring for you while you were dying and of then losing you came to a head. After several frantic phone calls, a palliative care doctor agreed to come to our house the next day.

She talked first to you, alone in your room, then to us as a family. She heard your laboured breathing and gave you medication to ease the discomfort. She asked you what was important, and you told her it was being present with us for whatever time it was you had left. The doctor looked at us, the caregivers, and saw the defeat in our eyes, the despair of trying to do a job we were never trained for. She offered the support we were desperate for and reassurance that our best was enough. With the medicine and care she brought with her, the doctor treated the family.

You died in May, just five days after the visit from the palliative care doctor. Those five days felt like the lifetime with 
you that we needed. After the doctor's visit, your focus could move from pain and suffering to family and loved ones; to thoughts and feelings, things never said, and stories already told a thousand times. You were present and alive. Then you died just as the doctor had explained to us, just as she had prepared us. On the fifth day, your breathing slowed down, further and further, until eventually it stopped all together. You were still.

In the fall I returned to school, this time as a medical student. And soon enough, after some time in the classroom, I was thrown onto the wards.
Although you were gone, in the hospital I saw you everywhere. With each patient I saw for a follow-up, a check-in, on the wards or in the emergency department, I thought of your words after the palliative care doctor had left that day. As I wandered into your room that evening to see how you were doing, you smiled for the first time in too long and you said to me, "That doctor reminded me of you. I hope when you're a doctor you make sure you always approach your patients with that same kindness."

I hope so, too.

Love,

Your girl

\section{Claire Moura}

Queen's University School of Medicine, Kingston, Ont.

This article has been peer reviewed.

This is a true story. The patient's daughter gave signed consent for it to be told.

Content licence: This is an Open Access article distributed in accordance with the terms of the Creative Commons Attribution (CC BY-NC-ND 4.0) licence, which permits use, distribution and reproduction in any medium, provided that the original publication is properly cited, the use is noncommercial (i.e., research or educational use), and no modifications or adaptations are made. See: https://creativecommons.org/ licenses/by-nc-nd/4.0/ 